\title{
Examining the terminology of race issues in assessments for international exchange students
}

\section{- Gavin Heron and Kevin Pilkington}

The rationale for this study emerged from teaching developments in a student exchange scheme between a university in Scotland and a university in a southern state of the USA. To date, exchange students on this scheme have participated in a taught classroom-based module. A possible development is for visiting students to undertake a practice placement in the UK. This study explored the terminology used by students in both countries when referring to race issues in assignments linked to practice. The terminology of race issues matters because, as Dominelli (2008: 8) reminds us, 'Words indicate understandings of reality, shape interactions within discourses that produce them, and expose specific conceptualisations of power relations and people's place in the world.' Examining students' assignments would provide some insight into their understanding of racism and the extent to which the terminology of race issues in existing assessment tools might be adapted for visiting students undertaking a placement in the UK.

\section{Relevance of the terminology of race issues}

Despite clear benefits for students and the good intentions of those organizing exchange schemes, Midgley (1992: 21) believes there are 'frequent cultural misunderstandings' of dominant ideologies and 
imperialist legacies. In terms of service users, Whitmore and Wilson (1997) believe the emphasis on partnership and collaboration within exchanges has had a minimal impact on improving the economic conditions for many of those in developing countries. Specific to student learning, Razack (2002: 251) believes the increasing interest in exchange schemes has not been accompanied by sufficient developments in pedagogy or practice and: 'Although individual benefits occur for students, there needs to be more focus on ways in which these international placement exchanges can enhance curriculum and practice in social work education.' Given the potential for exchange schemes to enhance cultural awareness and local knowledge (Nimmagadda and Cowger, 1999), a key way in which the curriculum might be enhanced is in ascertaining the most appropriate terminology for race issues. The centrality of assessment in the learning process is well established (Boud, 2000). Therefore, the terminology used in the assessment would appear to be an appropriate aspect to explore.

In Britain the term 'race' is used to represent a social construct rather than any discredited notion of the existence of different 'races' based on biological or physical characteristics. 'Race' is often placed in inverted commas as a way of recognizing this usage, although it is important to note that there is no consensus about the way this term should be integrated into social work practice in order to combat racism. For example, around a decade ago Potocky (1997: 324) argued that the UK 'is considerably ahead of the United States in the development and implementation of an anti-racism model'. The extent to which this remains the case is unclear. Keating (2000) believes less controversial terminology has been adopted in the UK in order to further marginalize an anti-racist perspective. More recently, Dominelli (2008: 4) believes that 'Today's climate for promoting anti-racist social work is bleak.' In the USA, some writers have replaced the concept of 'race' with the concept of cultural competence. Diller (2004: 61) states that 'it has become increasingly compelling to set aside the term race as a distinguishing feature between groups and to turn to cultural differences as a more useful and less controversial yardstick'. Diller (2004: 61) points out that cultural competence is not new and has been preceded in the human services by terms such as 'ethnic-sensitive practice', 'cross-cultural awareness', 'ethnic competence' and 'ethnic minority practice'. Lentin (2005) argues that certain changes in terminology in multiculturalism are cosmetic because the hierarchical ranking of humanity implicit in race is simply replicated under culture, where the dominant discourse is of integration, assimilation and a need for greater knowledge of other cultures. This is 
evident in, for example, the new terror dimension of Islamophobia, where cultural features such as religious differences and traditional dress, rather than quasi-science or biology, have been used to create fear and destroy social justice (Ahmed, 2003).

The use of such conflicting terminology may be reflected, at least to some extent, in the way practitioners conceptualize race issues. A study by Williams and Soydan (2005: 915) found social workers in European countries had a colour-blind approach to ethnicity and a preference for cultural/individual deficit models over structural explanations. In an analysis of a North American perspective, Razack and Badwall (2006: 665) state: 'Social workers of colour continue to sit on the margins of the profession because the global imagination of North Americans as white means that people of colour continue to sit on the periphery.' Examining the terminology of race issues in assignments may therefore give some indication of students' understanding of such issues and their preparedness for practice.

\section{Study design}

This study used written assignments to explore students' understanding of race issues. Two student cohorts participated in the study; one cohort was in the final year of an undergraduate programme in Scotland, and the other cohort was in the final year of a Master's degree in a southern state of the USA. Examining an undergraduate and postgraduate programme may seem inappropriate; however, these programmes represent the entry qualification into the profession in each country. The assignments selected for this study were the Integrated Practice Study (IPS) and Capstone ${ }^{1}$ assignment, which were undertaken by students in Scotland and the USA respectively. Although these assignments were not identical they do share important features that were of relevance to this study:

- both assignments are major pieces of work that are submitted towards the end of the programme and should, therefore, be an accurate reflection of students' thinking and understanding prior to qualifying;

- the assignments require students to link theory and practice based upon their experience on a practice placement;

- students are expected to understand and apply the knowledge, skills and values pertinent to social work practice;

- students must demonstrate an understanding of 'multicultural competence' (USA) and an ability to 'counter racism' (Scotland). 
It is important to recognize that any direct comparison is problematic because of the differences in areas such as legislation, culture, professional infrastructure, language and history of the two countries. Such differences are significant in many aspects, not least of all in terms of the ethnicity of the student cohorts. There was only one student from a minority ethnic group on the undergraduate programme in Scotland compared with the USA where almost half of the cohort was from black and minority ethnic groups. Despite such differences both assignments are major pieces of academic work linked to practice and therefore reflect important aspects of student learning about race issues prior to qualifying.

\section{Content analysis}

A content analysis using several single words as units was applied to the terminology relating to race issues in assignments. Cohen and Manion (1994: 56) highlight the potential value of a content analysis as a method of data collection:

In addition to elucidating the content of the document, the method may throw additional light on the source of the communications, its author, and on its intended recipients, those to whom the message is directed. Further, an analysis of this kind would tell us more about the social context and the kinds of factors stressed or ignored, and the influence of political factors, for instance.

Guidelines for the Capstone and IPS assignments focus on the term 'multicultural competence' and the ability to 'counter racism' respectively. Using only these terms for the content analysis is problematic because they do not encapsulate the range of terminology that might be referred to by students. For example, students may make reference to ethnicity, which would be encapsulated in the term 'multicultural', but not necessarily in the term 'racism'. In this study the two broad categories of race issues and ethnicity are used for the content analysis. Separating race issues and ethnicity could be considered misleading because these concepts overlap to some degree; however, while ethnicity is often associated with racism, it should not be confused with it (Sivanandan, 1982). The category of race issues included words such as 'racism', 'racial', 'racist', 'anti-racism' and 'anti-racist'. The category of ethnicity used words that might refer to minority and majority ethnic individuals and groups. Finally, some caution is required when applying a content analysis because of the controversy surrounding different terminology and the subjectivity of individual interpretations. Bonnett and Carrington (2000: 498) found the ethnic and racial categories frequently used by institutions are essentially flawed, with participants 
in their study often reporting them as 'nebulous, quaint and discrepant with commonly held subjective definitions'. Therefore, it would be misleading to assume there is shared meaning among students or tutors when using the terms associated with racism.

Permission to examine the assignments was sought from students and the departmental ethics committee sanctioned the study. The number of assignments selected for the study was determined by the need to have sufficient amounts of data for the content analysis while meeting certain resource constraints. From the social work programme in Scotland a sample of 31 assignments was randomly selected from a cohort of 47 students. Female students wrote 26 assignments and five were by male students. Of the cohort, 83 percent was female. All described themselves as white Scottish/British, except for one student who described herself as an Asian female. In the USA a sample of 32 assignments was randomly selected from a cohort of 51 students. Female students wrote 29 assignments and three were by male students. Of the cohort, 86 percent was female. Although the ethnicity of students who produced the assignments was not known, the cohort comprised mainly white students (slightly over half), African American students and a small number of students listed in the enrolment statistics as 'other groups'. The frequency of references to race and ethnicity is detailed and extracts from assignments have been cited.

\section{Results}

In the 31 IPS assignments in Scotland there was a total of 207 references, with 105 referring to race and 102 referring to ethnicity. In the 32 Capstone assignments in the USA there was a total of 678 references, with 136 referring to race and 542 referring to ethnicity. Overall, it would appear that students in the USA are more likely to make reference to race and ethnicity than students in Scotland. This difference is much greater in terms of the frequency of references to ethnicity. Students in Scotland tend to refer to race and ethnicity with equal frequency. Students in the USA, however, use the word ethnicity about four times more frequently than race. Every student from both cohorts made reference to ethnicity. Five students in the USA and three students in Scotland made no reference to race in assignments. In general, assessment guidelines about multicultural competence (USA) and countering racism (Scotland) are more likely to result in students making reference to ethnicity than race in assignments relating to practice.

The extent to which these terms were used in a way that conveyed any level of analysis in assignments was quite varied. Of the 
207 references to race and ethnicity by students in Scotland, 65 (31.4\%) demonstrated some analysis. Of the 678 references to race issues and ethnicity by students in the USA, 263 (38.8\%) demonstrated some analysis. Most of this analysis was in the form of an explanation. The following example is from a student in the USA: 'The reason this client had such a distrust of me was because I was Caucasian. As an African American, he saw my race and my DSS [Department of Social Services] position as threatening due to his experiences of racism and prejudice.'

There were few instances where students analysed race issues in ways that might, for example, recognize contradictions, use evidence to support a particular explanation, examine the implications of evidence or provide an alternative interpretation. Despite the differences between both cohorts, students often insert race issues and ethnicity into assignments in ways that convey limited levels of analysis.

\section{Range of terminology}

When referring to ethnicity, students in the USA used more varied terminology which included words or terms such as multicultural, multicultural competence, cultural competence, cultural differences, cross-cultural competence, dominant culture, subcultures, diversity, discrimination, oppression, stereotyping, prejudice, white privilege, segregation, ethnic, cultural identity, people of colour, blacks, Eurocentric, Anglo-American, African American, Caucasian, Appalachians, Hmong, Latino culture and heritage. For students in Scotland, the category of ethnicity included words or terms such as minority ethnic, ethnic minorities, discrimination, oppression, anti-discriminatory practice and antioppressive practice. Other words such as nationality, culture, diversity and religion were also used, but much less frequently, and were only included in the content analysis when they referred to ethnicity or race issues.

Only one student from the USA used the term 'anti-racism' in the assignment. Ten students (32\%) in Scotland made reference to anti-racism/anti-racist practice and it was most commonly expressed in relation to the provision of information: 'In order to provide policies and procedures that are fully anti-discriminatory and anti-racist I feel it would be more beneficial to have information provided in other languages and to have this information more easily accessible to people from ethnic communities.'

There were very few examples of incidents or situations where students actually challenged racism. When it occurred, it was generally 
limited to challenging the racist views of clients: 'I have challenged [the client] when he expresses racial views and jokes. On reflection, I am aware of my own values and suggested to [the client] that this is learned behaviour, but must be challenged.'

Overall, the term 'anti-racism' does not appear to be a common feature of students' written work in Scotland and is used even less frequently by students in the USA.

\section{Restricting the location of race issues}

References to race issues were not evenly spread throughout assignments and similar patterns emerged in both student cohorts. There was a concentration of references in the "context' ${ }^{2}$ section of the assignments produced by students in Scotland. This section is at the beginning of the IPS, varied in length between approximately 150 and 600 words, and included information about, for example, the function of the agency, geographical location and the size of team. For 12 students (38\%) this was the only section where references to race issues were made. Although such references are important, they were seldom accompanied by an explanation of why they might be relevant to the practice placement. For example, despite several students highlighting the need to challenge racism, there was often little explanation or analysis of how this might be undertaken or achieved in terms of practice at an individual, cultural, institutional or structural level. The Capstone assignment, unlike the IPS, is structured in such a way that students have to write under five main sections: 'multicultural competence'; 'advanced knowledge and skills for complex direct practice'; 'advanced knowledge and skills for complex indirect practice'; 'knowledge and skills for research and evaluation'; and 'self-reflection and summary'. The section on multicultural competence accounted for most of the references to race issues. Twenty-six of the 32 students referred to race in this section. There was no mention of race by any students in the section on 'advanced knowledge and skills for complex direct practice'. Four students made reference to race in the section 'advanced knowledge and skills for complex indirect practice'. Four students referred to race in the section on 'knowledge and evaluation'. Finally, seven students referred to race in the section on 'self-reflection and summary'. This suggests that although both assignments are directly related to practice placements, students seldom refer to race issues in relation to their practice. 


\section{A gap between experience and writing}

It would be erroneous to assume that the limited reference to race issues in relation to direct practice reflected a racially harmonious environment in which students undertake fieldwork either in Scotland or the USA. A student in Scotland referred to the experience of a black child at school: 'the persistent racial abuse could have impacted negatively on his cognitive functioning, therefore lowering his self-esteem and self-worth'.

A student in the USA noted: 'I have personally seen the effects of organized racism in the larger community on the quality of education provided to African American and Hispanic children.'

Accounts of being subjected to racism differed between the two student cohorts. None of the students in Scotland wrote about any racism directed towards them during the practice placement. Given there was only one black student, the likelihood of white/black colour racism being directed towards a student may be rather small. There were, however, no references to any other forms of racism based on other factors or characteristics. Several students in the USA discussed the racism they experienced in their practice: 'I recall a situation in which a client became irate with me and left a message on my answering machine calling me the " $\mathrm{N}$ " word.'

When visiting a client's home another student stated that: "[the child's] father stated they did not feel comfortable talking with a "colored" counselor. Although [the child] and his parents agreed to continue to allow [the child] to work with me due to the waiting list for other counselors it became evident following several insensitive and biased remarks that there would be enormous cultural barriers for [the child] and I to overcome to address the issues that facilitated his referral for treatment.'

Of particular interest is the student's preference for the word 'biased'. Isn't this student experiencing racism, and if so, why is it not labelled as such? This tendency to label racism as something else was not an isolated occurrence. Another student, for example, labels an incident in terms of cultural differences rather than racism: 'There were very few African-Americans in this town and I had to visit homes with confederate flags on their porch. In many instances, when I visited these homes, the client would not acknowledge me, they would only communicate with my Caucasian counterpart. In any event, I learned that creating a respectful relationship with clients is important when establishing rapport, and although the clients did not respect me and my cultural differences I maintained a level of respect for them.' 
Given many of the students in the USA commented on the high quality of teaching in relation to multicultural competence, it is not clear why some students seemed to avoid referring specifically to racism.

\section{Discussion}

A content analysis detailing the way students from two different countries use the terminology of race in major assignments provides some insight into their understanding of racism prior to qualification. Future research that incorporates other academic institutions and exchange schemes between industrialized and developing countries might provide a more robust analysis. The complex nature of the terminology of race issues becomes more apparent when the assessment process has to bridge two countries, which have significant differences in, for example, culture, legislation and professional practice. Does 'multicultural competence' in the USA and an ability to 'counter racism' in Scotland have similar meaning to each cohort of students, and is one more useful in helping individuals to conceptualize and challenge racism? The findings in this study suggest the terminology in existing assessment tools may need to be adapted for both domestic students and those participating on an exchange scheme in the UK. Students in Scotland used the categories of race and ethnicity with similar frequency, whereas their counterparts in the USA referred to ethnicity approximately four times more frequently than race. To this extent, 'multicultural competence' may steer students towards the terminology of ethnicity rather than race. This may explain, at least in part, why only one student in the USA made reference to anti-racism. While the frequency of references to race reveals certain differences, there was an important commonality in the way different terminology was used by both cohorts of students.

Although students in the USA used a much wider range of terminology, approximately two-thirds of references to race and ethnicity by both cohorts did not incorporate any analysis. Many references to race appeared to be dropped into assignments in ways that provide little understanding of racism. This level of superficiality does not appear to be entirely random, as references to race issues were often restricted to a particular section of the IPS and Capstone assignment. Of course, if no section headings were used in assessments (e.g. multicultural competence), there may be even fewer references to race issues. However, unless headings are meaningful and aligned to the realities of practice, they may be counterproductive. According to Lentin (2005), changes in terminology, from race to cross-cultural awareness or ethnic competence, coincide with an absence of any rigorous critique of the state 
apparatus, a prerequisite for allowing human difference and racism to be viewed in terms of multiculturalism. This may help to explain why much of the terminology of race issues in assignments was confined to a discourse of description.

If written assignments are to reflect students' experiences, antiracism seems the most appropriate terminology to use in assessments that might encourage an exploration of racism in practice. Put simply, is there a more logical contrasting label to racism than anti-racism? Only 11 of the 63 students in this study made reference to the terms 'anti-racism' or 'anti-racist'. The authors suggest that social work educators adopt the terminology of anti-racism in assessments if students are to make judgements in considering alternatives to racism. At present, such action might be at odds with institutional practices in the UK. Dominelli (2008: 4) criticizes key institutions such as the General Social Care Council in the UK for not having anti-racism as 'a separate requirement of assessment but one to be incorporated into values teaching'. The submergence of anti-racism in the broader terminology of values and the desire to use less controversial terminology (Keating, 2000) may not only undermine the development of students' analytical skills in relation to racism. A lack of analysis of the social processes and structures in which racism is embedded may also reflect a gap in knowledge of the way it intersects with other forms of oppression, such as sexism, classism, ageism and heterosexism.

\section{Implications for black and minority ethnic students}

The consequences of maintaining the status quo are not the same for all students. Several black students in this study gave narratives of personal experiences of racism that were undoubtedly humiliating, hurtful and threatening. Unless resisted and challenged there is a risk that such differences could become embedded in the assessment processes, where certain identities and experiences are valued or denied in ideologies, policies and practices that sustain power relations of superior and inferior along racial lines. The appeal for some black students in the USA of labelling the personal experience of racism on placement as 'something else' may reflect their own insidious position prior to qualifying. If control can be wielded in institutions to suffocate, destroy or suppress key issues with the intention of 'redefining the boundaries of what is to count as a political issue' (Lukes, 1974: 19), is it not possible that some students might be reluctant to challenge certain iniquitous institutional practices when the very same institutions apply inappropriate terminology in the assessments used to evaluate their written work and practice? 
Perhaps the descriptive discourse of race issues in assignments is also augmented in some instances by avoidance - re-labelling or re-defining racism as something less threatening to the status quo.

Dealing with racism, Avril et al. (2003: 278) recognize that 'We find ourselves revisiting similar questions over time but constantly need to find different responses, informed by previous practice but situated in current social and cultural contexts.' The terminology in assignments needs to be located in a discourse of analysis that reflects the evolving nature of racism, such as the terror dimension of Islamophobia. In doing so, greater emphasis might be placed on the ethnicity and race of the dominant group, a point of focus where Hall's (1980) ideas on hegemonic subordination by the dominant group remain relevant to 21 st-century social work. Though there was only one black student in the cohort from Scotland and it was therefore less likely that experiences of racism might occur, there was little discussion about the dominance of whiteness or institutional racism in either cohort. Discussing international social work and inequality, Razack and Badwall (2006: 663 ) believe it is 'critical to be mindful of whose voices continue to be privileged in such a discourse'. If this is absent, it is difficult to assess whose voices students might privilege in their practice. A suitable assessment for international exchange students might require a discussion of whiteness, which according to Bonnett and Carrington (2000: 498) "would imply that "white" people need to think about themselves - more specifically, their shifting ethnic identities - in a somewhat similar fashion to the way "non-white" people have been required to do for many years'. Terminology that encourages white students to think in similar ways to black and minority ethnic students on race issues, might also help them to recognize Garrett's (2002) viewpoint: that an anti-racist perspective must include some analysis of the diversity that exists in the dominant ethnic group. This may contribute to a more liberating learning environment which empowers students to explore racism in relation to practice, rather than choose to ignore it or label it as something else.

\section{Conclusion}

The findings in this study suggest that the existing terminology for race issues in assignments may not be serving students' best interests, either by allowing racism to be marginalized from practice or located in a discourse of avoidance or description. Rather than view exchange schemes as things that make assessments over-complex, they can be used to develop more appropriate terminology for domestic and international 
students. Redressing the gaps in learning and practice might begin by having social work educators committed to an explicit reference to antiracism as a requirement in assessments linked to practice. If this option is rejected, it may be worth considering how the terminology of race issues in social work assessments is instrumental in recognizing the existence of racial inequality, or compliant with its denial. As Diller (2004: 46) reminds us, most people of colour find 'race and racial inequity are ever-present realities. To deny them must seem either deeply cunning or bordering on the verge of psychosis.'

\section{Acknowledgement}

The authors would like to thank the Carnegie Trust for their support in undertaking this study.

\section{Notes}

1. The Capstone also requires students to append five of their most significant learning assignments completed during the programme. This study did not examine these assignments as part of the analysis of the Capstone.

2. Students are advised to structure the IPS with a 'context' heading near the beginning of the assignment, which should include information about the placement.

\section{References}

Ahmed, A.S. (2003) Islam Under Siege: Living Dangerously in a Post-honor World. Oxford and Malden, MA: Polity Press and Blackwell.

Avril, B., T. Elliott and N. Stopard (2003) 'Living up to the Standards We Set: A Critical Account of the Development of Anti-racist Standards', Social Work Education 22(3): 271-82.

Bonnett, A. and B. Carrington (2000) 'Fitting into Categories or Falling Between Them? Rethinking ethnic classification', British Journal of Sociology of Education 21(4): 487-500.

Boud, D. (2000) 'Sustainable Assessment: Rethinking Assessment for the Learning Society', Studies in Continuing Education 22(2): 151-67.

Cohen, L. and L. Manion (1994) Research Methods In Education, 4th edn. London: Routledge.

Diller, J.V. (2004) Cultural Diversity. Belmont, CA: Brooks/Cole.

Dominelli, L. (2008) Anti-racist Social Work, $3^{\text {rd }}$ edn. Basingstoke: Palgrave Macmillan.

Garrett, P.M. (2002) “"No Irish Need Apply": Social Work in Britain and the History and Politics of Exclusionary Paradigms and Practices', British Journal of Social Work 32(4): 477-94.

Hall, S. (1980) 'Race, Articulation and Societies Structured in Dominance', in UNESCO (ed.) Sociological Theories: Race and Colonialism, pp. 305-45. New York: UNESCO.

Keating, F. (2000) 'Anti-racist Perspectives: What Are the Gains for Social Work?', Social Work Education 19(1): 77-87. 
Lentin, A. (2005) 'Replacing "Race", Historicizing "Culture" in Multiculturalism', Patterns of Prejudice 39(4): 379-96.

Lukes, S. (1974) Power: A Radical View. Basingstoke: Macmillan Press.

Midgley, J. (1992) 'The Challenge of International Social Work', in M.C. Hokenstad, S.K. Khinduka and J. Midgley (eds) Profiles in International Social Work, pp. 13-27. Washington, DC: NASW Press.

Nimmagadda, J. and C.D. Cowger (1999) 'Cross-cultural Practice: Social Work Ingenuity in the Indigenization of Practice Knowledge', International Social Work 42(3): 261-76.

Potocky, M. (1997) 'Multicultural Social Work in the United States: A Review and Critique', International Social Work 40: 315-26.

Razack, N. (2002) 'A Critical Examination of International Student Exchanges', International Social Work 45(2): 251-65.

Razack, N. and H. Badwall (2006) 'Regional Perspectives . . f from North America', International Social Work 49(5): 661-6.

Sivanandan, A. (1982) A Different Hunger: Writings on Black Resistance. London: Pluto Press.

Whitmore, E. and M. Wilson (1997) 'Accompanying the Process: Social Work and International Development Practice', International Social Work 40(1): 57-74.

Williams, C. and H. Soydan (2005) 'When and How Does Ethnicity Matter? A CrossNational Study of Social Work Responses to Ethnicity in Child Protection Cases', British Journal of Social Work 35: 901-20. 